\title{
Potato tuber phospholipids contain colneleic acid in the 2-position
}

\author{
Marie-Laure Fauconnier ${ }^{\mathrm{a}}$, Todd D. Williams ${ }^{\mathrm{b}}$, Michel Marlier ${ }^{\mathrm{a}}$, Ruth Weltic,* \\ ${ }^{a}$ Unité de Chimie Générale et Organique, Faculté Universitaire des Sciences Agronomiques de Gembloux, Passage des Déportés 2 , \\ B-5030 Gembloux, Belgium \\ ${ }^{\mathrm{b}}$ Mass Spectrometry Laboratory, University of Kansas, Lawrence, KS 66045, USA \\ ${ }^{c}$ Division of Biology, Ackert Hall, Kansas State University, Manhattan, KS 66506, USA
}

Received 31 January 2003; revised 8 February 2003; accepted 8 February 2003

First published online 24 February 2003

Edited by Ulf-Ingo Flügge

\begin{abstract}
Colneleic acid $\left(9-\left[1^{\prime}(E), 3^{\prime}(Z)\right.\right.$-nonadienyloxy]-8(E)nonenoic acid) is produced from linoleic acid by the sequential action of 9-lipoxygenase and divinyl ether synthase. We demonstrate that a small fraction of the colneleic acid in potato tubers is esterified in phospholipids. This colneleic acid was released by chemical hydrolysis and a phospholipase $A_{2}$, but not by a lipase with 1-acyl specificity. Phosphatidylcholine, phosphatidylethanolamine, and phosphatidylinositol contain molecular species with nominal masses consistent with identification as palmitoyl, colneleoyl species. Exact mass analysis of its fragments confirmed the identity of palmitoyl,colneloyl phosphatidylinositol. To our knowledge, this work represents the first identification of a colneleoyl phospholipid.
\end{abstract}

(C) 2003 Published by Elsevier Science B.V. on behalf of the Federation of European Biochemical Societies.

Key words: Colneleic acid; Potato; Oxylipin; Phospholipid; Mass spectrometry

\section{Introduction}

Colneleic acid $\left(9-\left[1^{\prime}(E), 3^{\prime}(Z)\right.\right.$-nonadienyloxy]-8(E)-nonenoic acid or 9-oxa-8-trans,10-trans,12-cis-linoleic acid) has been detected in both the tubers and the leaves of potato [1,2]. The 9-hydroperoxide of linoleic acid is formed from linoleic acid by a 9-lipoxygenase, and this is converted to colneleic acid by a divinyl ether synthase $[1,2]$. Colneleic acid levels rise in potato leaves after Phytophthora infestans infection, and colneleic acid is believed to play a role in plant response to pathogen infection [2]. In potato tubers, suppression of the lipoxygenase, Lox1, that forms 9-hydroperoxides alters tuber development, but the role of colneleic acid in tubers is unclear [3].

Synthesis of colneleic acid, like that of other oxylipins, appears to be at least mainly carried out on free fatty acid substrates, although some plant lipoxygenases have the capability to act on glycerolipids as well as free fatty acids [4]. Recently it was discovered that another plant oxygenated fatty acyl species, 12-oxophytodienoic acid, is largely esterified to monogalactosyldiacylglycerol [5]. Here we identify colneleic acid in the complex lipid fraction of potatoes and identify

*Corresponding author. Fax: (1)-785-532 6653.

E-mail address: welti@ksu.edu (R. Welti).

Abbreviations: ESI, electrospray ionization; fwhh, full width at halfheight; MS, mass spectrometry; MS/MS, tandem mass spectrometry PC, phosphatidylcholine; PE, phosphatidylethanolamine; PI, phosphatidylinositol; TOF, time of flight 1-16:0,2-colneleic phosphatidylinositol (PI) as a phospholipid species that contains colneleic acid.

\section{Materials and methods}

\subsection{Extraction of potato lipids}

Potato tubers (Bintje) (750 g) were frozen in liquid nitrogen and ground to a powder. The powder was added to 1.21 of isopropanol at $75^{\circ} \mathrm{C}$, containing $0.01 \%$ butylated hydroxytoluene. After $15 \mathrm{~min}$ at $75^{\circ} \mathrm{C}, 600 \mathrm{ml}$ of chloroform and $500 \mathrm{ml}$ of water were added. The mixture was agitated for $30 \mathrm{~min}$ at room temperature. The potato powder was re-extracted three times with chloroform/methanol $(2: 1$, $\mathrm{v} / \mathrm{v}$ ) containing $0.01 \%$ butylated hydroxytoluene. The solvent was pooled and then washed with 11 of $1 \mathrm{M} \mathrm{KCl}$. The organic phase was filtered and the solvent was evaporated to dryness in a rotary evaporator.

\subsection{Isolation of potato lipid PI-enriched fraction (fraction 5 )}

The lipid $(7.1 \mathrm{~g})$ was dissolved in chloroform and applied to a $20 \mathrm{~g}$ silicic acid column, packed in chloroform. The column was eluted sequentially with the same volume $(15 \mathrm{ml} / \mathrm{g}$ silicic acid or $300 \mathrm{ml})$ of each of the following: (1) chloroform, (2) acetone, (3) chloroform/ methanol $(95: 5, \mathrm{v} / \mathrm{v}) ;(4)$ chloroform/methanol $(80: 20, \mathrm{v} / \mathrm{v})$; (5) chloroform/methanol $(50: 50, \mathrm{v} / \mathrm{v}) ;(6)$ methanol. This sequence of elution solvents was described by Christie [6]. The solvent was evaporated from fraction 5 with a rotary evaporator. Fractions 1 , 2, and 3 were analyzed by thin layer chromatography (TLC) on silica gel in petroleum ether $\left(60-95^{\circ} \mathrm{C}\right) /$ diethyl ether/formic acid $(6: 4: 1.5)$ and detected with iodine vapor. Fractions 4,5 , and 6 were analyzed with chloroform/methanol/acetic acid/water $(8.5: 1.5: 1: 0.3)$ and detected with iodine vapor.

\subsection{Lipase treatment of fraction 5}

To release the fatty acyl groups in the 1-position of the phospholipids in fraction $5,40 \mathrm{mg}$ of lipid was dispersed in $1 \mathrm{ml}$ of $50 \mathrm{mM}$ Tris- $\mathrm{HCl}, \mathrm{pH} 7.5 .10 \mathrm{mg}$ of Candida rugosa lipase (Sigma, L-1754, $890 \mathrm{U} / \mathrm{mg}$ ) was dissolved in $5 \mathrm{ml}$ of $50 \mathrm{mM}$ Tris- $\mathrm{HCl}, \mathrm{pH} \mathrm{7.5.} \mathrm{An}$ aliquot $(50 \mu \mathrm{l})$ of the lipase solution was added to the lipid dispersion, and the mixture was incubated for $2 \mathrm{~h}$ at $37^{\circ} \mathrm{C}$. To release the fatty acyl groups in the 2-position of the phospholipids in fraction $5,40 \mathrm{mg}$ of lipid was dispersed in $1 \mathrm{ml} 50 \mathrm{mM}$ Tris- $\mathrm{HCl}, \mathrm{pH} 8.9 .100 \mathrm{mg}$ of Streptomyces violaceoruber phospholipase $\mathrm{A}_{2}$ (Sigma, P-8685, 10 $\mathrm{U} / \mathrm{mg}$ ) was dissolved in $1 \mathrm{ml}$ of $50 \mathrm{mM}$ Tris- $\mathrm{HCl}, \mathrm{pH}$ 8.9. An aliquot $(90 \mu \mathrm{l})$ of the phospholipase solution was added to the lipid dispersion, and the mixture was incubated for $2 \mathrm{~h}$ at $37^{\circ} \mathrm{C}$. Each of two reaction mixtures (1-acyl lipase and the phospholipase $\mathrm{A}_{2}$ ) was extracted for $10 \mathrm{~min}$ at room temperature with $2 \mathrm{ml}$ of diethyl ether, and re-extracted the same way two more times. The ether was evaporated from the combined extracts of each lipase reaction, and the extracts were re-dissolved in $200 \mu$ l acetonitrile.

2.4. Chemical hydrolysis of fraction 5

$120 \mathrm{mg}$ of fraction 5 was dissolved in $3 \mathrm{ml}$ of $2 \mathrm{~N} \mathrm{NaOH}$ in methanol/water $(5: 1, \mathrm{v} / \mathrm{v})$. Nitrogen was bubbled through the sample. The solution was heated $1 \mathrm{~h}$ at $70^{\circ} \mathrm{C} .9 \mathrm{ml}$ of water was added, and the $\mathrm{pH}$ was lowered to 1 with $4 \mathrm{~N} \mathrm{HCl}$. The mixture was extracted three times with $10 \mathrm{ml}$ of diethyl ether, each time for $10 \mathrm{~min}$ at room 
temperature. The ether was evaporated, and the residue was dissolved in $100 \mu \mathrm{l}$ of acetonitrile and filtered.

\subsection{Extraction of potato tubers and addition of standard for free colneleic acid determination}

15-Hydroxy-11,13-eicosadienoic acid (15-HEDE, internal standard) $\left(400 \mu \mathrm{l}\right.$ of $1.8 \times 10^{-4} \mathrm{M}$ ) was added to $5 \mathrm{~g}$ of potato tuber powder. The powder was extracted with $15 \mathrm{ml}$ of diethyl ether at room temperature for $10 \mathrm{~min}$. The powder was re-extracted with $10 \mathrm{ml}$ of diethyl ether for $10 \mathrm{~min}$ at room temperature and the ether fractions were pooled and dried with anhydrous sodium sulfate. The solvent was evaporated to dryness under nitrogen and the extracted compounds were redissolved in $100 \mu 1$ of acetonitrile. A blank was made with the same protocol omitting the potato powder.

\subsection{Colneleic acid determination by HPLC}

15-HEDE was used as an internal standard. The analysis was performed with a Hewlett Packard series 1050 high performance liquid chromatography (HPLC) (with diode array detector) on an Inertsil $250 \times 4.6 \mathrm{~mm} 5$ ODS- 2 column (Chrompack, Middelburg, The Netherlands) with a flow rate of $0.7 \mathrm{ml} / \mathrm{min}$. Solvent A was water $(0.01 \%$ $\mathrm{v} / \mathrm{v}$ trifluoroacetic acid); solvent $\mathrm{B}$ was acetonitrile $(0.01 \% \mathrm{v} / \mathrm{v}$ trifluoroacetic acid). Elution conditions were: 0-61 min, 47\% solvent A; 61-63 min, a gradient from $47 \%$ A to $20 \%$ A; $63-74 \mathrm{~min}, 20 \%$ A; $74-75 \mathrm{~min}$, from $20 \%$ A to $0 \%$ A; $75-95 \mathrm{~min}, 100 \% \mathrm{~B}$. For reequilibration, the flow was continued from 95 to $100 \mathrm{~min}$ with a gradient from $0 \% \mathrm{~A}$ to $47 \% \mathrm{~A}$, and from 100 to $105 \mathrm{~min}$ at $47 \% \mathrm{~A}$. Identification of colneleic acid was based on its UV spectrum and retention time by comparison with the pure compound synthesized, extracted, purified by preparative HPLC, derivatized, and characterized by gas chromatography-mass spectrometry (MS) analysis according to Rusterucci et al. [7].

\subsection{MS/MS precursor ion scanning}

Potato extract in chloroform/methanol/300 $\mathrm{mM}$ ammonium acetate in water (300:665:35) was analyzed by electrospray ionization tandem MS (ESI-MS/MS), as previously described [8].

\subsection{Q-TOF mass spectral analysis}

The solvent was evaporated from fraction 5 , and fraction 5 was dissolved in chloroform/methanol $(2: 1, \mathrm{v} / \mathrm{v})$. The sample was diluted so that the final composition of the solvent for mass spectrometry was chloroform/methanol/300 $\mathrm{mM}$ ammonium acetate in water (300: 665:35). This sample was infused at $30 \mu \mathrm{l} / \mathrm{min}$ into the ESI source of a Micromass Q-Tof-2 (Midid (Micromass, Manchester, UK) operated in negative ion mode. ESI-MS spectra were acquired with the time of flight (TOF) analyzer tuned for maximum resolution (10000 RP full width at half-height (fwhh)) and argon in the collision cell. The cone voltage was $40 \mathrm{~V}$ and the collision cell was at $10 \mathrm{~V}$. Collision-induced dissociation spectra were acquired with the MS1 quadrupole tuned to

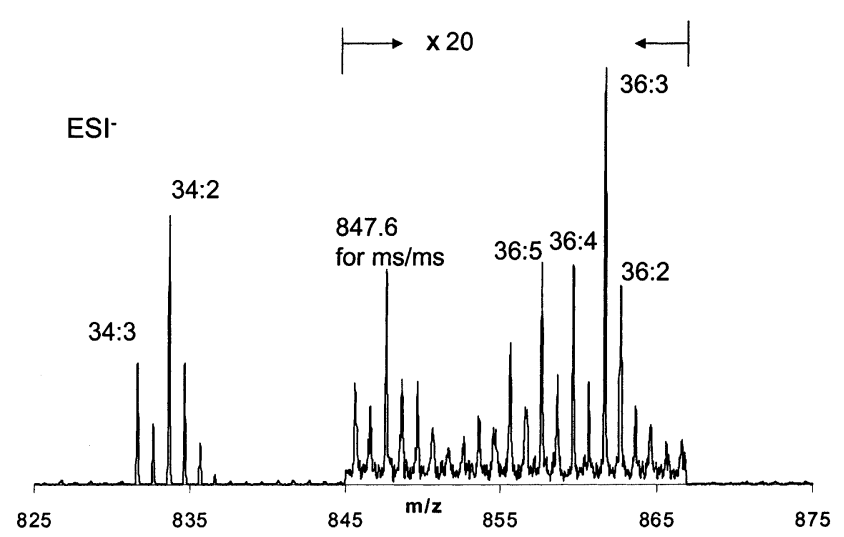

Fig. 1. ESI-MS of silicic acid column fraction 5 in the range of $\mathrm{m} / \mathrm{z}$ 825 to $\mathrm{m} / z$ 875. This fraction is enriched in PI, and all of the peaks in this mass range correspond to PI species. The species are labeled as total number of acyl carbons:total number of double bonds. Note that the spectrum in the range of $m / z$ 845-867 is expanded 20fold in relation to the rest of the spectrum. The species at 847.6 was analyzed further by MS/MS.

transmit a monoisotopic species at 847.6 and product ions were collected for $5 \mathrm{~min}$ of acquisition time to increase signal to noise. Collision gas was the same as for MS1 acquisition, and the collision energy was varied during the $5 \mathrm{~min}$ from 25 to $45 \mathrm{eV}$ to obtain a good distribution of product ions. Acyl carboxylate ions were observed with maximum yields at $35 \mathrm{~V}$. All TOF spectra were acquired with the daily mass calibration, and collision-induced dissociation spectra were mass corrected with a fragment common to PIs, $\mathrm{C}_{9} \mathrm{H}_{14} \mathrm{O}_{9} \mathrm{P}_{1}$ (297.0375).

\section{Results}

Crude fractionation of potato extracts by silicic acid column chromatography resulted in six lipid fractions with increasing polarity. TLC analysis demonstrated that fraction 1 contained simple lipids, fraction 2 contained galactolipids, and fraction 3 contained phosphatidic acid. Fractions 4 and 5 were the two major phospholipid fractions. TLC, as well as mass spectrometric analysis, showed that fraction 5, which was eluted with chloroform/methanol (50:50), contained only phospholipids, including PI and some phosphatidylcho-

Table 1

Low mass fragments of $m / z 847$ in the negative mode

\begin{tabular}{|c|c|c|c|c|c|}
\hline Mass detected & $\begin{array}{l}\text { Description of } \\
\text { fragment }\end{array}$ & Formula & $\begin{array}{l}\text { Theoretical } \\
\text { mass for formula }\end{array}$ & $\begin{array}{l}\text { Mass difference } \\
\text { (detected minus theoretical) } \\
\text { (millimass units) }\end{array}$ & $\begin{array}{l}\text { Width of peak } \\
\text { (amu fwhh) }\end{array}$ \\
\hline 153 & $\begin{array}{l}\text { glycerophosphate } \\
\text { minus } 1 \mathrm{H}_{2} \mathrm{O}[8]\end{array}$ & $\mathrm{C}_{3} \mathrm{H}_{6} \mathrm{O}_{5} \mathrm{P}$ & 152.9953 & +0.4 & 0.029 \\
\hline 223 & $\begin{array}{l}\text { phosphoinositol } \\
\text { minus } 2 \mathrm{H}_{2} \mathrm{O}[10]\end{array}$ & $\mathrm{C}_{6} \mathrm{H}_{8} \mathrm{O}_{7} \mathrm{P}$ & 223.0008 & +0.5 & 0.048 \\
\hline 241 & $\begin{array}{l}\text { phosphoinositol } \\
\text { minus } 1 \mathrm{H}_{2} \mathrm{O}[10]\end{array}$ & $\mathrm{C}_{6} \mathrm{H}_{10} \mathrm{O}_{8} \mathrm{P}$ & 241.0113 & -0.5 & 0.040 \\
\hline 259 & $\begin{array}{l}\text { phosphoinositol } \\
{[10]}\end{array}$ & $\mathrm{C}_{6} \mathrm{H}_{12} \mathrm{O}_{9} \mathrm{P}$ & 259.0219 & +0.3 & 0.048 \\
\hline 297 & $\begin{array}{l}\text { glycero-phosphoinositol } \\
\text { minus } 1 \mathrm{H}_{2} \mathrm{O}[10]\end{array}$ & $\mathrm{C}_{9} \mathrm{H}_{14} \mathrm{O}_{9} \mathrm{P}$ & 297.0375 & $\begin{array}{l}0.0 \\
\text { (used for calibration) }\end{array}$ & 0.053 \\
\hline 315 & $\begin{array}{l}\text { glycero-phosphoinositol } \\
{[10]}\end{array}$ & $\mathrm{C}_{9} \mathrm{H}_{16} \mathrm{O}_{10} \mathrm{P}$ & 315.0481 & -0.9 & 0.045 \\
\hline 255 & $16: 0$ & $\mathrm{C}_{16} \mathrm{H}_{31} \mathrm{O}_{2}$ & 255.2324 & -0.8 & 0.037 \\
\hline 269 & $17: 0$ & $\mathrm{C}_{17} \mathrm{H}_{33} \mathrm{O}_{2}$ & 269.2481 & +0.6 & 0.044 \\
\hline 279 & $18: 2$ & $\mathrm{C}_{18} \mathrm{H}_{31} \mathrm{O}_{2}$ & 279.2324 & -0.4 & 0.049 \\
\hline 293 & colneleic acid & $\mathrm{C}_{18} \mathrm{H}_{29} \mathrm{O}_{3}$ & 293.2117 & See Fig. 3 & 0.074 (see Fig. 3) \\
\hline 293 & $19: 2$ & $\mathrm{C}_{19} \mathrm{H}_{33} \mathrm{O}_{2}$ & 293.2481 & See Fig. 3 & 0.074 (see Fig. 3) \\
\hline
\end{tabular}


line (PC) and phosphatidylethanolamine (PE), although fraction 4 was more enriched in PE. The most abundant negatively charged ions produced by electrospray of fraction 5 were PIs. Chemical hydrolysis of $120 \mathrm{mg}$ of fraction 5 released $3.0 \mathrm{nmol}$ of colneleic acid (25 pmol/mg fraction 5), indicating that a small amount of this oxylipin was incorporated in a phospholipid or phospholipids. Treatment of fraction 5 with a 1-acyl-specific lipase did not release detectable colneleic acid, but treatment of $40 \mathrm{mg}$ of fraction 5 with phospholipase $\mathrm{A}_{2}$ released $0.9 \mathrm{nmol}$ colneleic acid $(22 \mathrm{pmol} / \mathrm{mg}$ fraction 5$)$, indicating that the colneleic acid was esterified to a phospholipid or phospholipids in the 2-position.

To identify phospholipid species containing colneleic acid, lipid profiles of unfractionated potato extracts were obtained by ESI-MS/MS precursor scanning. Scans for the precursors of headgroup-specific fragments yield spectra of each headgroup class $[8,9]$. The spectra indicated that several classes of lipids contained minor peaks with masses that corresponded to the masses of a 16:0-colneleoyl pair. The phospholipid species detected included positively charged ions of PC at $m / z 772$ and PE at $m / z 730$ and a negatively charged PI ion at $\mathrm{m} / \mathrm{z}$ 847. Because few other components of the potato lipid mixture have masses near the mass of the PI species, this species was chosen for fragment analysis to determine the structure of its acyl components.

To analyze the acyl structure of the PI at $\mathrm{m} / \mathrm{z} 847$, fraction 5 from the silicic acid chromatography was utilized. Fraction 5 was enriched in PI and a mass spectrum of fraction 5 in the mass range 825-875 showed that the components detected in this mass range corresponded to various PI species (Fig. 1). Fragmentation in the negative mode of the peak at $\mathrm{m} / \mathrm{z} 847$ with the Micromass Q-Tof produced several fragments (Fig. 2). Exact mass analysis of the fragments indicated that five of the fragments were derived from the PI headgroup [10] (Table 1). No fragments of lipids from other headgroup classes were identified in the material with $\mathrm{m} / \mathrm{z} 847$. Four fragments were compatible with identification as acyl species. One acyl combination included species at $\mathrm{m} / \mathrm{z} 269$ and $\mathrm{m} / \mathrm{z} 279$, which corresponded to heptadecanoic (17:0) acid and linoleic (18:2) acid, respectively. The second acyl combination included species at $\mathrm{m} / \mathrm{z} 255$ and $\mathrm{m} / \mathrm{z}$ 293. The peak at $\mathrm{m} / \mathrm{z} 255$ corresponded to palmitic (16:0) acid. Careful analysis of the peak near $\mathrm{m} / \mathrm{z} 293$ showed that this peak was wider than the other peaks and the mass corresponding to the center of the peak did not correspond exactly to the mass of a reasonable chemical formula for the fragment. Instead, the mass of the center of the peak was between the mass of colneleic acid and that of nonadecadienoic $(19: 2)$ acid. Modeling of this peak indicated that this peak contained both species (Fig. 3). Thus,

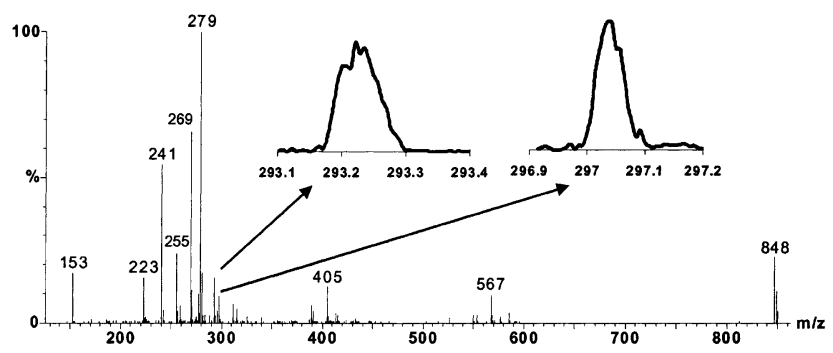

Fig. 2. Collision-induced spectrum (MS/MS) from $\mathrm{m} / \mathrm{z}$ 847.6. The insets show the peak widths at $\mathrm{m} / \mathrm{z} 293$ and $\mathrm{m} / \mathrm{z} 297$.

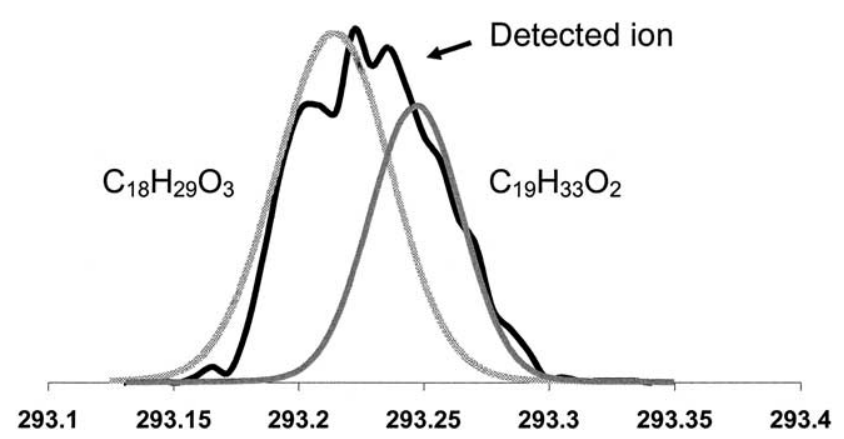

Fig. 3. Spectrum of mass-corrected ion at 293 from the collision-induced dissociation spectrum of $\mathrm{m} / \mathrm{z}$ 847.6. The black line represents the detected ion with fwhh $0.074 \mathrm{amu}$. The light gray line (left) represents a simulated ion of 0.04 amu fwhh for the formula $\mathrm{C}_{18} \mathrm{H}_{29} \mathrm{O}_{3}$ (colneleoyl anion). The dark gray line (right) represents a simulated ion of $0.04 \mathrm{amu}$ fwhh for the formula $\mathrm{C}_{19} \mathrm{H}_{33} \mathrm{O}_{2}$ (19:2 anion).

the peak at $m / z 847$ was composed of 17:0-18:2 PI, 16:0colneleoyl PI, and 16:0-19:2 PI.

\section{Discussion}

This work describes the first identification of a colneleoyl phospholipid in vivo and demonstrates that colneleic acid is esterified to the 2-position of the phospholipids. Colneleic acid is an ether lipid species found in plants. To our knowledge, colneleoyl phospholipids have not been identified previously. However, phospholipids containing epoxyeicosatrienoic acids have been identified in the 2-position of PI and PE from rat liver [11]. Recently, Stelmach and coworkers [5] showed that the bulk of 12-oxophytodienoic acid in Arabidopsis rosettes is esterified in 1-(12-oxophytodienoyl),2-(hexadecatrienoyl) monogalactosyldiacylglycerol. Lipase treatment released 1-2 $\mu \mathrm{g}$ of 12-oxophytodienoic acid per g Arabidopsis fresh weight. In wounded leaves, the levels of 12-oxophytodienoyl-containing monogalactosyldiacylglycerol reached $20 \mu \mathrm{g} / \mathrm{g}$ fresh weight. In contrast, only about $2 \mathrm{ng} / \mathrm{g}$ potato fresh weight was freed from the phospholipids of silicic acid column fraction 5. Since fraction 5 represented a sizable fraction of total potato phospholipids and since potato tubers contained about $3 \mu \mathrm{g}$ (10 $\mathrm{nmol}$ ) colneleic acid per $\mathrm{g}$ potato fresh weight, the data suggest that colneloyl-containing phospholipids accounted for a small fraction of the total colneleic acid pool.

On the other hand, the data demonstrate that colneleic acid was specifically esterified to the 2-position of the phospholipids in a fraction enriched in PI. In PI, as in other phospholipids synthesized by the plant extra-plastidic pathway, the 2-position is likely to contain nearly all 18-carbon fatty acids, such as linoleic acid [12]. The localization of colneleic acid to the 2-position of the phospholipids implies that the colneloyl phospholipids were generated enzymatically, but it is unclear whether the colneleic acid was generated from linoleic acid while esterified to the phospholipid or whether colneleic acid was incorporated into the phospholipid fraction after synthesis from free linoleic acid. 9-Lipoxygenase activity in potato tubers apparently occurs in the cytoplasm [4,13,14]. Since PC, $\mathrm{PE}$, and PI are found primarily in extra-plastidic locations, the cytoplasmic location of the lipoxygenase leaves open the possibility that this enzyme might occasionally use an intact phospholipid as a substrate in vivo. Thus, it is possible that colneleoyl phospholipids are 'accidental' products of enzymes 
that are promiscuous toward their substrates. On the other hand, colneleoyl phospholipids may play an as yet unknown role in tuber physiology.

Acknowledgements: This work was supported by the National Science Foundation (MCB-0110979 to R.W. and T.D.W.). The Q-Tof was purchased with support from NSF EPSCoR and the University of Kansas. M.L.F. is a postdoctoral researcher of the Fonds National de la Recherche Scientifique of Belgium.

\section{References}

[1] Galliard, T. and Phillips, D.R. (1972) Biochem. J. 129, 743-753.

[2] Weber, H., Chételat, A., Caldelari, D. and Farmer, E.E. (1999) Plant Cell 11, 485-493.

[3] Kolmiets, M.V., Hannapel, D.J., Chen, H., Tymeson, M. and Gladon, R.J. (2001) Plant Cell 13, 613-626.

[4] Feussner, I. and Wasternack, C. (2002) Annu. Rev. Plant Biol. 53, 275-297.

[5] Stelmach, B.A., Müller, A., Hennig, P., Gebhardt, S., Schubert-
Zsilavecz, M. and Weiler, E.W. (2001) J. Biol. Chem. 276, 12832 12838.

[6] Christie, William W. (1982) Lipid Analysis, 2nd edn, Permagon Press, Oxford, England.

[7] Rusterucci, C., Montillet, J.L., Agnel, J.P., Battesti, C., Alonso, B., Knoll, A., Bessoule, J.J., Etienne, P., Suty, L., Blein, J.P. and Triantaphylades, C. (2002) J. Biol. Chem. 274, 36446-36455.

[8] Brügger, B., Erben, G., Sandhoff, R., Wieland, F.T. and Lehmann, W.D. (1997) Proc. Natl. Acad. Sci. USA 94, 2339-2344.

[9] Welti, R., Li, W., Li, M., Sang, Y., Biesiada, H., Zhou, H.-E., Rajashekar, C.B., Williams, T.D. and Wang, X. (2002) J. Biol. Chem. 277, 31994-32002.

[10] Hsu, F.F. and Turk, J. (2000) J. Am. Mass Spectrom. 11, 986999.

[11] Capdevila, J.H., Kishore, V., Dishman, E., Blair, I.A. and Falck, J.R. (1987) Biochem. Biophys. Res. Commun. 146, 638-644.

[12] Miquel, M., Cassagne, C. and Browse, J. (1998) Plant Physiol. 117, 923-930.

[13] Royo, J., Vancanneyt, G., Pérez, A.G., Sanz, C., Störmann, K., Rosahl, S. and Sánchez-Serrano, J.J. (1996) J. Biol. Chem. 271, 21012-21019.

[14] Porta, H. and Rocha-Sosa, M. (2002) Plant Physiol. 130, 15-21. 